\title{
The Effectiveness of Varied Forms of Education in Influencing Attitudes and Behaviors Towards Veganism
}

\author{
Ava Seiffer ${ }^{1}$ \\ ${ }^{1}$ Maura Large Chadwick School, Palos Verdes Peninsula, CA, USA \\ ABSTRACT
}

In today's society, the number of socially conscious people is rising as information becomes increasingly available. Veganism is one expression of social consciousness and while a diet that abstains from animal products dates back to the days of Native Americans, a poll conducted by Gallup found that only three percent of the United States population is vegan (McCarthy).

Many studies previously conducted have synthesized the reasons why people choose to be vegan, but none of them have touched on how to best shift attitudes and behaviors of non-practitioners. According to a Vomad study, $68 \%$ of vegans were abstaining from consuming animals due to the ill-treatment of animals by society. This means that a large population of practitioners adopted veganism through becoming educated about the treatment of animals.

The origins of veganism are rooted in Native Americans' notions of duality with nature. Modern philosophical theories regarding the treatment of animals that are intended to educate society includes Ecological Animalism, focused on the dualism between humans and nature, and Ontological Veganism, focused on the equality of all living beings and the morality of inflicting pain on others. People for the Ethical Treatment of Animals (PETA), a provegan organization, has chosen to educate through polarizing marketing and social media campaigns. This poses my research question: How effective is education on the philosophies of veganism in influencing non-vegans' attitudes and behaviors as compared to education through polarizing marketing and social media campaigns?

\section{History}

As veganism becomes increasingly popular, many people have lost sight of the origins of the plant-based lifestyle. In North America, the lifestyle dates back to the time of Native Americans. For example, the Choctaw Indians, who roamed Mississippi and Oklahoma, were resourceful and survived on vegetables and used them not only for nutrition but also for building shelters and tools (Laws). By understanding that the United States' original inhabitants maintained vegan lifestyles, one can understand how such a lifestyle can be readily achieved in modern society.

The notion of duality between humans and animals stems from the Native Americans' belief system. Cherokee Native Americans believed that all needs of humans and animals could be met without manslaughter or aggression (Laws). This duality has been maintained throughout time from the Cherokees' notion of karma. Karma is defined as destiny or fate, following as effect from cause. Cherokees believed that when man became greedy and used an animal, the remaining animals invented diseases to keep the human population in check (Laws). This idea reinforced the duality between humans and animals, resulting in consequences for those who did not respect such duality.

As veganism became more modernized due to the progression of society, many influential people enforced the notion of duality in different ways. The Greek philosopher Pythagoras practiced a lifestyle that in modern times would be called raw vegan. Pythagoras called people following the same lifestyle as him Pythagoreans, as the term 
"vegetarian" was coined in 1815 (Moran). In the 20th century, Mahatma Gandhi exemplified duality and nonviolence through not only political actions but his food choices as well. Gandhi's search for a healthy diet led him towards veganism because it did not cause harm to other living beings (Moran). While veganism can now be practiced healthily, Gandhi did not have access to many resources that are available to modern-day vegans and, as a result of his diet, he became ill. Following his illness, Gandhi implemented locally sourced milk back into his diet to create a healthy balance in his body and his reliance on animals (Vermillion).

The term "vegan" was developed by Donald Watson in 1944. It meant "non-dairy vegetarian" but by 1945 also involved abstaining from eggs, honey, animals' milk, butter, and cheese. It was not until 1951 that the Vegan Society defined vegan as the doctrine that man should live without exploiting animals.

\section{The Product Types Ontology: Class Definition for 'Veganism'}

Throughout the 1960s and 1970s, Dick Gregory influenced a broadening of the demography of people joining the vegan community. Gregory served as a civil rights activist and his teachings continue to influence members of the African American community to become vegan. Gregory spoke frankly about the unhealthy foods that many African Americans ate, highlighting both the ill-treatment of cows in factory farms and the processing of animals from slaughterhouses. Gregory's lectures caused many people to look inwardly at the quality of their own lives, specifically through the lens of food (BWHI).

In the 1980s, PETA was created to fight for animal rights, promote duality, and produce pro-vegan propaganda in the hopes of turning people's attitudes towards veganism (Moran, 2016). Today, veganism is becoming mainstream with chains such as Mark \& Spencer, Wagamama, and Pizza Hut all offering vegan options and Guinness stopping the use of fish bladders in its brewing process (Hancox).

As veganism has become more widespread, health challenges have emerged, particularly among neonatal children. A 1979 study found that children of vegan mothers could have depressed growth rates (Dickerson 682) and a 2003 study found goiter, a rare condition, in both a vegan mother and her child due to a lack of iodine in their diet (Shaikh 111). Last, in 2007 a six-week-old toddler, who had been fed primarily soy milk and apple juice, died and his vegan parents were convicted of murder (Planck). Education around a safe diet should be a priority for all provegan organizations, particularly given the systematic bias shown by vegans regarding health problems in a vegan diet. Research has found that participants in online discussions on veganism primarily attribute responsibility for health deficiencies to the individual practice of veganism rather than the overall ideology itself (Sneijder 675).

\section{Related Case Studies}

Research shows that people choose veganism for a variety of different reasons, and there have been several studies performed regarding the synthesization of the vegan population. Based on a Vomad study, it was found that $81 \%$ of vegans surveyed were women. While researchers hypothesize that this could be largely due to societal pressure put on women's body image, over $68 \%$ of all surveyed participants were abstaining from consuming animals due to the ill-treatment of animals by society. The survey also showed the accessibility of veganism, given that $50 \%$ of participants went straight to veganism without any intermediate step to vegetarianism.

Other studies have been performed with the intent of connecting veganism with vegetarianism through statistics regarding why people have chosen to adopt one of these lifestyles. One study conducted by Dr. Lisa Johnson, a professor of environmental law and animal law at the University of Puget Sound, looked into people's devotion to animalism and compared that devotion to the definition of a religion. Johnson's survey evidenced why veganism should potentially be recognized as a religion under United States law (Johnson 31).

The only outreach-type study was performed by researchers working for the Department of Agricultural and Food Marketing at the University of Kassel. The researchers tracked consumers' physical weight and attitudes 
after being vegan for a controlled period. The aim was to identify different motivations for those who enjoyed the vegan diet and to understand the behaviors of those who did not enjoy the vegan lifestyle. The study also followed its subjects' attitudes towards animal agriculture and showed the consumers' overall change in attitude as measured through survey questions and the subjects' intentions of adopting or maintaining a plant-based diet (Janssen 643). While the study raised people's awareness, it also demonstrated that the main motivation for maintaining a plantbased diet was the subjects' inherent pressures to improve their appearance.

Each of these studies has created data points on veganism and contrasts between those who are vegan and those who are not; unfortunately, none have identified exactly why people resist adopting a vegan lifestyle and whether behaviors can be changed with education.

\section{Ecological Animalism}

To understand the significance of veganism, and potentially convince non-vegans to adopt veganism, one must understand the philosophies those who pursue a plant-based diet have towards animals. Ecological Animalism, created by Val Plumwood in 2012, means to foster a dialogue of the ethics of sharing and creating a partnership between humans and animals and depicts why animals should not be treated with malice (Plumwood 2). Ecological Animalism is a nuanced way of depicting the dualism between humans and nature and, while the notion of dualism is very clear, certain philosophers have historically challenged the idea of Ecological Animalism entirely (Blatti).

Plumwood presented her theory of Ecological Animalism as the two-way conversation between people and animals in the context of a sensitive vegetarian position. She specifically seeks to expose the poor treatment of animals in slaughterhouses and factory farming operations as being in opposition to the notion of a dualistic human/animal partnership (Plumwood 290).

History shows that philosophers have at times considered and rejected the idea of human/animal dualism upon which Ecological Animalism is based. John Locke, an English philosopher in the 17th century, introduced the human/animal power imbalance and believed that the moral responsibility of humans was to protect themselves rather than a human-animal or animal to which the human has formed a connection. He argued that persons but not humananimals are linked in productive ways (Blatti). The fallacy in Locke's argument, from an Ecological Animalism perspective, lies in the fact that Locke uses speciesism to justify his classifications, which is evidenced by accepting the intelligence of certain animals by calling them human-animals. Locke exercises speciesism by creating a claim that the knowledge possessed by human-animals is not comparable to that of a person. The notion of Ecological Animalism helps to support a portion of Locke's claim of persons needing interactions with other intelligent organisms to live a full life. However, Ecological Animalism rejects Locke's notion of a person being a ranking, calling it a sortal concept (Melin 71). A person is a "function of kind" and persons are those able to think in specific patterns and "is rational...ordinarily conscious and aware of itself as tracing a path through time and space... morally accountable for its actions." Therefore, a person could be an animal, creating illegitimacy to Locke's claim.

\section{Ontological Veganism}

A philosophical subsect of veganism is the study of what moral issues inspired people to become vegan. This expansion behind a person's behavior is known as moral vegetarianism (Doggett). Elements of moral vegetarianism are based on the pain and suffering of animals. It is assumed that humans, and presumably animals as well, have an interest in avoiding pain and suffering, and therefore, anyone who proposes to subject another being to pain and suffering should have their consent. Since animals are not capable of providing such consent, the issue of pain and suffering in animals becomes complicated (Deckers 60-61).

Moral vegetarianism is professionally recognized as Ontological Veganism. Val Plumwood created the term to describe opposition to the use of animal products on the psychological basis derived from viewing animals 
as ethical subjects systematically equal to human beings (Plumwood 1). This definition validates the lives of animals and forces people to deeply reconsider their attitude towards animals. Ontological Veganism advocates for the total boycotting of animal products (Plumwood 1).

One criticism of Ontological Veganism is that it is not culturally sensitive to apply universal standards of behavior to all cultural groups. For example, the Inuit, a group of indigenous people inhabiting the Arctic regions, face unique cultural and environmental hurdles which Ontological Veganism fails to recognize (Sturgeon 155). The controversy surrounding Ontological Veganism has also come from within the feminist community. Veganism and vegetarianism have been adopted as a feminist practice with certain advocates claiming that meat's prestige and caloric content, and its association with physical violence, is affiliated with masculinity and is to be avoided (Clark 6). This alignment of feminism and Ontological Veganism has been disputed by others who state that, since it is more difficult for women and children to succeed on vegan diets, the philosophy is unfair and discriminatory (Lucas 156157).

\section{Polarizing Marketing of Veganism}

Vegans are sometimes considered to be self-righteous environmentalists who are too proud to admit when they have shifted into the extremist side of the enthusiasm spectrum; however, this raises a question as to whether the polarizing marketing and social media campaigns of pro-vegan organizations are effective in creating behavioral change?

The most convincing social reactions to propaganda and advertisements occur when marketers use highly artificial techniques to evoke an emotion (Schanck and Goodman 107). Swaying a crowd through emotion is most effectively done by allowing the subjects to complete a questionnaire. The questionnaire allows subjects to be subtly moved into agreeing with extremist views, while also feeling completely in control (Schanck and Goodman 107). Many advertisements can be considered propaganda. According to Dr. Philip Taylor of the University of Leeds, propaganda, while oftentimes having a malicious connotation, is actually neither good nor evil; it is simply the organization of methods used to persuade people to form a certain opinion on a controversial matter (Vidal 1). Propaganda was largely used during wartimes; however, it is now a foundation for many marketing campaigns.

Interestingly, polarization in the animal-consumption debate has been almost entirely created by pro-vegan organizations. PETA is a very controversial pro-vegan organization. Currently, the organization is running a campaign to end the bigotry demonstrated when people justify discrimination against animals. In this campaign, PETA uses strongly worded statements to invoke guilt in the reader or viewer. For example, PETA states: "The enjoyment that someone may get from casting a baited hook into the water to catch fish can't matter more than the pain inflicted on them when they're pierced through the lip and yanked into an environment in which they can't breathe." This sentence is meant to persuade readers to humanize and feel empathy for the fish and not to contribute to the illtreatment of these animals. PETA is also working to show that when people treat companion animals differently than commercial animals, they are promoting speciesism. A large sub-campaign running alongside the \#EndSpeciesism campaign is the "All Beings Bleed The Same" poster campaign. In the poster, people are shown inside slaughterhouses brutally beating the most commonly sold commercial animals. The meaning behind both campaigns is to promote Ontological Veganism and exemplify how wrong it is to kill any type of animal.

Unfortunately, the campaigns of pro-vegan advocates occasionally push the boundaries of the truth. For example, claims in the Netflix documentary "What the Health" included the misstatements that eating an egg a day is as bad as smoking five cigarettes and that a daily serving of processed meat raises the risk of diabetes by 51 percent (Brody). Such misstatements potentially make all pro-vegan messaging less credible.

There is not an example of a group solely devoted to the harming or mass killing of animals; however, there are groups that protect the Second Amendment to the United States Constitution. One of these organizations is the National Rifle Association (NRA) which argues for the protection of the Second Amendment and believes that hunting is an American tradition, as hunters' rights are being actively protected by the NRA Institute for Legislative Action (NRA). While the NRA's views may seem extremist to many, the NRA's methods are not particularly polar- 
izing as compared to the marketing messages from certain pro-vegan organizations. The NRA does not use any specific examples of being pro-death or animal massacre on their website, and instead, they present hunting as a traditional American pastime, appealing to a broad audience.

In conclusion, the marketing that pro-vegan organizations use is often intense and emotion-evoking. Since these viewpoints are not countered directly by pro-gun and pro-hunting organizations, it may appear to be overwhelming for those who do not have a strong opinion on the subject. The impact of pro-vegan marketing efforts, and their possible overreach, has not been quantified to date and it is worthwhile to study and consider their effectiveness in influencing the behavior of non-vegans.

\section{Methods}

The purpose of this project was to determine the most effective methods to educate non-vegans regarding veganism with the goal of influencing their attitudes and behaviors. The project used a series of survey questions to analyze the effectiveness of education focused on the philosophies of veganism as compared to education through polarizing marketing and social media campaigns. To begin, human participants were anonymously asked a series of questions to identify their baseline attitude towards their diet, their likelihood to modify the consumption of animal proteins in their diet, and the key obstacles to modifying their current behaviors.

Following the baseline questions, participants were given an educational description of Ecological Animalism, a philosophy regarding the duality between humans and animals. Following the informational section regarding Ecological Animalism, participants were asked to provide a series of responses, based on a Likert scale, to demonstrate their degree of agreement or disagreement towards statements geared to gauge their implicit views on Ecological Animalism. Participants were next given an educational description of Ontological Veganism, a philosophy opposing the consumption of all animal products. Following the informational section regarding Ontological Veganism, participants were asked to provide a series of responses, based on a Likert scale, to demonstrate their degree of agreement or disagreement towards statements geared to gauge their implicit views on Ontological Veganism. Following the section on Ontological Veganism, participants answered once again the original baseline questions regarding their likelihood to modify the consumption of animal proteins in their diet and key obstacles to modifying their current behaviors. In combination, the Ecological Animalism and Ontological Veganism survey responses were intended to gauge participants' likelihood to modify their current behaviors based solely on education regarding the philosophies of veganism.

Participants then viewed a series of videos and marketing images, each of which contained highly polarizing content regarding the treatment of animals in society. After viewing the videos and marketing images, participants once again answered the original baseline questions regarding their likelihood to modify the consumption of animal proteins in their diet and key obstacles to modifying their current behaviors. Through comparison of the survey participants' responses at each stage of the survey, and each step of their educational journey regarding veganism, the effectiveness of varying forms of education on survey participants can be observed. Specifically, the impact of highly polarizing educational content on survey respondents' likelihood to modify consumption of animal proteins in their diet can be observed and a determination can be made as to whether exposure to these materials positively or negatively impacted survey respondents' attitudes and behaviors towards veganism. The project required a broad group of participants ranging from adolescents to those 65 or more years of age. Participants included both men and women in the South Bay of Los Angeles, California, an area with a population of 139,773 people. All participants have or are pursuing high school education. According to the Census ACS 1-year survey, the 2017 median household income for the South Bay area of Los Angeles was $\$ 116,540$, which was $38.4 \%$ higher than the California median. Although data were predominantly obtained from upper-middle-class citizens, diversity in age and race yield a multitude of representations in this study.

Participants were personally solicited for their participation. Each participant devoted approximately 15 minutes to reviewing information and completing survey responses. All participants completed the same survey and 
viewed the same informational materials. Data was collected for three weeks to maximize diversity in responses. Participants were emailed the survey; however, data collection

was anonymous to ensure that responses could not be correlated to specific participants and to avoid bias and pressure within the responses. The survey was conducted using Google Forms, a tool that allows collecting information via a personalized survey medium. Use of this tool allowed participants to participate in the survey and answer questions on their own time. After the survey was completed, participants could no longer retake it to avoid multiple responses which could have skewed the data.

Data was evaluated based on the average number of respondents to each question and through observation of shifts in responses, evaluated along the Likert scale, after each phase of exposure to educational materials. Through these observations, shifts in respondents' attitudes after exposure to education regarding the philosophies of veganism can be determined and the shifts in respondents' attitudes after exposure to polarizing educational materials can be isolated and evaluated.

\section{Measure}

All survey questions were developed by the author. The survey was composed of four sections: demographic information, measurement of baseline diet and attitudes, measurement after education regarding the philosophies of Ecological Animalism and Ontological Veganism, and measurement after exposure to polarizing, pro-vegan marketing, and social media content. The majority of questions were created with the Likert scale, with each response rated on a one to five scales with a rating of one representing "strongly disagree" and a rating of five representing "strongly agree". Certain questions, including those regarding demographics, and questions regarding the respondent's current diet and the primary obstacle to changing their diet towards eliminating the use of animal proteins and byproducts, were designed as multiple-choice questions. The survey's data collection yielded 93 total responses.

\section{Results}

The results from each section were first analyzed to identify the respondents' initial baseline attitudes. These measures were compared to respondents' attitudes after completing the other sections of the survey after new educational information had been presented to them. The comparison of the baseline attitudes to attitudes after the respondent was exposed to the initial educational information, and the comparison of the second set of attitudes to attitudes after exposure to additional, more polarizing educational materials, enables one to determine the change in attitudinal shifts caused by the presentation of each module of new educational information. The purpose of this format of synthesization is to enable data from the results to directly follow the format of the research question: How effective is an education focused on the philosophies of veganism in influencing non-vegans' attitudes and behaviors as compared to education through polarizing marketing and social media campaigns? On an overall basis, the population of respondents who participated in this study were effectively influenced, and persuaded to shift their attitudes towards the elimination of animal proteins and the elimination of animal byproducts, and consequently towards veganism, as a result of education on the philosophies of Ecological Animalism and Ontological Veganism; however, the collective results also yielded the determination that respondents' attitudes shifted towards veganism to a greater extent after exposure to, and education through, the viewing of polarizing, pro-vegan marketing and social media content.

\section{Data Content}

The participant group was comprised of 54 females and 39 males. Age was varied with $40.9 \%$ less than 18 years old; $18.3 \%$ had ages ranging from $18-34$ years old; $31.2 \%$ having ages ranging from $35-54$ years old, and $9.7 \%$ more 
than 54 years old. The race was also varied with $69.9 \%$ identifying as white; $11.8 \%$ identifying as Asian; $10.8 \%$ identifying as African American, and 7.5\% identifying as Latino.

Participants answered baseline questions regarding their diet with $81.7 \%$ identifying as carnivores who eat all animal products; $9.7 \%$ identifying as pescatarians who eat only fish proteins; $7.5 \%$ identifying as a vegetarian who does not eat animal protein but does consume animal proteins, and 1.1\% identifying as vegan and do not consume any animal products. In the baseline, $51.6 \%$ of participants disagreed with the statement, "I may change my diet during the next 12 months," and only $30.1 \%$ agreed. A baseline measurement of $51.6 \%$ disagreed with the statement, "I may change my diet to eliminate one or more animal proteins during the next 12 months," while $31.2 \%$ agreed. When the question became more limiting and asked, "I may change my diet to eliminate all animal proteins during the next 12 months," a full 79.6\% disagreed and only 11.8\% agreed. Last, similar baseline results were derived from the question, "I may change my diet to eliminate the use of all animal byproducts (i.e. milk, eggs, cheese, etc.) during the next 12 months," with $77.4 \%$ disagreeing with the statement and only $15.1 \%$ agreeing. When asked a baseline question regarding the primary obstacle to changing their diet towards eliminating the use of animal proteins and byproducts, $48.4 \%$ of participants responded that they enjoy eating meat and $30.1 \%$ responded that inconvenience and family food preferences were a limiting factor.

Following the baseline survey responses, participants were exposed to a series of questions intended to provide education regarding the philosophy of Ecological Animalism. To measure the extent to which participants understood, and were aligned towards, Ecological Animalism, participants were provided a series of statements that supported Ecological Animalism and were asked to either agree or disagree with those statements. An overwhelming $74.2 \%$ of participants agreed with the statement, "I experience sadness if I am aware of cruelty or harm towards animals," while only 12.9\% disagreed. A full 50.5\% agreed with Ecological Animalism's notion of dualism through their response to the question, "I think humans and animals exist in a mutually beneficial relationship," while $24.7 \%$ disagreed. Interestingly, more respondents, representing $34.4 \%$ disagreed with the statement, "I think it is OK for one species to modify the natural ecosystem for their own needs. (i.e. factory farming of protein sources)," than agreed, with only $29.1 \%$ agreeing.

At this point, the second philosophy, Ontological Veganism was introduced. Statements in this survey section were designed to assess the degree to which participants supported Ontological Veganism. An overwhelming $92.5 \%$ of participants agreed with the notion that "Animals (non-humans) are capable of developing relationships towards each other," while only $4.4 \%$ disagreed. Similarly, $91.4 \%$ also agreed with the statement "Animals are capable of developing relationships with other species (i.e. humans)," with only $4.3 \%$ expressing disagreement. Participants representing $80.7 \%$ also agreed that "Animals are capable of feelings similar to humans. (i.e. sadness, joy, and grief)," while only $8.6 \%$ disagreed. Nearly all respondents agreed with the Ontological Veganism philosophy that animals are sentient beings, as $94.6 \%$ agreed with the statement, "Animals are capable of feeling and experiencing pain."

After being educated on both philosophies, participants were asked the same set of baseline questions regarding potential changes in their diet, as well as a question regarding the primary obstacle to changing their diet towards eliminating the use of animal proteins and byproducts. This was completed to measure attitudinal shifts after receiving education regarding the philosophies of veganism. After education on the philosophies, $32.3 \%$ of participants agreed, and $46.2 \%$ disagreed, with the statement, "I may change my diet during the next 12 months." This represents a net increase of $2.2 \%$ of participants who are now considering changing their diet and a decrease of $5.4 \%$ in the number who are not considering changing their diet. The number of respondents who agreed with the statement, "I may change my diet to eliminate one or more animal proteins during the next 12 months," increased by $4.3 \%$ while the number of respondents who disagreed was reduced by $7.5 \%$. Similarly, the same indicia of movement occurred among participants asked the statement, "I may change my diet to eliminate all animal proteins during the next 12 months," with participants agreeing with the statement increasing by $4.3 \%$ and those disagreeing declining by $12.9 \%$. The number of respondents who answered that they may consider veganism through their agreement with the question, "I may change my diet to eliminate the use of all animal byproducts (i.e. milk, eggs, 
cheese, etc.) during the next 12 months," increased by $2.1 \%$ and those disagreeing declined by $7.5 \%$. The respondents' primary obstacle to changing towards veganism shifted from respondents enjoying meat, which declined by $2.2 \%$, to participants now considering it inconvenient or inconsistent with their family's food preferences, which increased $1.1 \%$.

Last, participants were shown a series of polarizing, pro-vegan marketing, and social media campaigns to see if the visual effects and sensationalist content further influenced their attitudes. After viewing the media, 33.3\% of participants agreed with the statement "I may change my diet in the next 12 months," while $42.0 \%$ disagreed. Those who agreed represents a net increase of $1.0 \%$ from the attitude that was registered after education on the philosophies of veganism; similarly, the number of participants who disagreed declined by $4.2 \%$ from the attitude that was registered after education on the philosophies of veganism. After the media exposure, $36.6 \%$ of participants agreed, and $44.1 \%$ disagreed, with the statement, "I may change my diet to eliminate one or more animal proteins during the next 12 months." This represents an increase of $1.1 \%$ in those agreeing and no change in the quantity of those disagreeing which registered after education on the philosophies of veganism; however, the number strongly disagreeing with the statement decreased by $2.1 \%$, which shows a positive shift and an erosion of extreme negative sentiment. Delving into the data further, the number of participants who agreed with the statement, "I may change my diet to eliminate all animal proteins during the next 12 months," increased by $4.4 \%$, while those who disagreed with the statement increased $2.1 \%$. Finally, there was a $3.3 \%$ increase in participants who agreed with the statement, "I may change my diet to eliminate the use of all animal byproducts (i.e. milk eggs, cheese, etc) during the next 12 months," and a $6.4 \%$ decrease in the number who disagreed with the statement. The obstacles identified by participants in changing their behavior also shifted. The number of people who enjoyed eating meat as the primary obstacle declined from $46.2 \%$ to $40.9 \%$ and the obstacle of inconvenient or inconsistent with their family's food preferences increased from $31.2 \%$ to $33.3 \%$. Overall, the data demonstrate the significant effect of education through exposure to polarizing, pro-vegan marketing, and social media content in influencing non-vegans' attitudes and behaviors towards veganism.

It is necessary to review the limitations of the study which may weaken the conclusions. This study was limited in its sample size with 93 total responses. In addition, responses were skewed to female respondents. While responses were diverse in age range, they were skewed towards a younger group of respondents. Last, responses were primarily derived from individuals in a small part of southern California which influenced the socio-economic composition and possibly skewed answers as compared to the overall United States population.

Overall, this study confirmed the effectiveness of education in positively influencing non-vegans' attitudes and behaviors. Education regarding the philosophies of Ecological Animalism and Ontological Veganism was found to affect a measurable shift in non-vegans' attitudes and behaviors towards a vegan lifestyle with both a reduction in respondents who were unlikely to change their behavior and an increase in respondents who were likely to change their behavior. When the same respondents were then provided additional education through the exposure to polarizing, pro-vegan marketing, and social media content their behaviors shifted even further with a notable increase in respondents who affirmatively indicated that they would shift towards a more vegan lifestyle. Furthermore, after exposure to polarizing marketing and social media content, the primary obstacle to a change in diet notably shifted away from the respondents' enjoyment of meat and towards the issue of inconvenience and family food preferences. Based on these observations and conclusions, the next stage of research would be to focus on the development of educational materials designed to address the convenient ways in which a vegan lifestyle could be incorporated into people's daily lives and serve the needs of their family's diet.

\section{Acknowledgments}

I would like to thank my school, my advisor Ms. Maura Large, family, friends, and especially my father. 


\section{Bibliography}

Blatti, Stephan, “Animalism”, The Stanford Encyclopedia of Philosophy (Fall 2019 Edition), Edward N. Zalta (ed.), https://plato.stanford.edu/archives/fall2019/entries/animalism/.

Brody, Jane E. "Good Vegan, Bad Vegan." The New York Times, 2 Oct. 2017, www.nytimes.com/2017/10/02/well/eat/good-vegan-bad-vegan.html Accessed 20 Dec. 2019.

BWHI Staff. (2016, December 6). "How Dick Gregory Inspired One Woman To Become a Vegan.” Retrieved from Black Women's Health Imperative website: https://bwhi.org/2016/12/06/dick-gregory-inspired-one-woman-becomevegan/.

Clark, Dylan. "The Raw and the Rotten: Punk Cuisine." Ethnology, vol. 43, no. 1, 2004, pp. 19-31. JSTOR, www.jstor.org/stable/3773853. Accessed 16 Jan. 2020.

Deckers, Jan. "The Ethics of Qualified Moral Veganism." Animal (De)Liberation:

Should the Consumption of Animal Products be Banned? Ubiquity Press, 2016, pp. 51-106. JSTOR, www.jstor.org/stable/j.ctv3t5qmj.6. Accessed 16 Jan. 2020.

Dickerson, J. W. T., et al. "Malnutrition In Infants Receiving Cult Diets."

The British Medical Journal, vol. 1, no. 6164, 1979, pp. 682-683. JSTOR, www.jstor.org/stable/25431504. Accessed 16 Jan. 2020.

Doggett, Tyler, "Moral Vegetarianism", The Stanford Encyclopedia of Philosophy ( Fall 2018 Edition), 14 Sept. 2018, Edward N. Zalta (ed.), <https://plato.stanford.edu/archives/fall2018/entries/vegetarianism/>.

Hancox, Dan. "The Unstoppable Rise of Veganism: How a Fringe Movement went Mainstream." The Guardian, 2016, www.theguardian.com/lifeandstyle/2018/apr/01/vegans-are-coming-millennials-health-climate-changeanimal-welfare. Accessed 20 Dec. 2019.

Janssen, M., Busch, C., Rodiger, M., \& Hamm, U. (2016). "Motives of Consumers Following a Vegan Diet and their Attitudes Towards Animal Agriculture." Appetite, vol. 105, 1 October 2016, pp. 643-651. Retrieved from Science Direct database. http://www.sciencedirect.com/science/article/abs/pii/S0195666316302677.

Johnson, Lisa. "The Religion of Ethical Veganism." Journal of Animal Ethics, vol. 5, no. 1, 2015, pp. 31-68. JSTOR, www.jstor.org/stable/10.5406/janimalethics.5.1.0031. Accessed 16 Jan. 2020.

Laws, R., Ph.D. (1994, September). Native Americans and Vegetarianism. Retrieved November 21, 2019, from International Vegetarian Union website: https://www.nativeamericacalling.com/monday-july-16-2018-plant-based-natives/.

Lucas, Sheri. "A Defense of the Feminist-Vegetarian Connection." Hypatia, vol. 20, no. 1, 2005, pp. 150-177. JSTOR, www.jstor.org/stable/3810847. Accessed 16 Jan. 2020.

McCarthy, Niall. "Who Are America's Vegans And Vegetarians? [Infographic]." Forbes, 6 Aug. 2018, www.forbes.com/sites/niallmccarthy/2018/08/06/ who-are-americas-vegans-and-vegetariansinfographic/\#336a55a8211c. Accessed 20 Dec. 2019. 
Melin, Roger, “Animalism and Person as a Basic Sort”, Argument, (Vol. 1), Jan. 2011, pp. 69-85. http://philpapers.org/archive/MELAAP.pdf.

Moran, V. (2016, December). A brief history of veganism. Retrieved November 21, 2019, from Main Street Vegan website: https://mainstreetvegan.net/ a-brief-history-of-veganism-by-victoria-moran/.

Planck, Nina. "Death By Veganism." The New York Times, 21 May 2007, www.nytimes.com/2007/05/21/opinion/21planck.html. Accessed 20 Dec. 2019.

Plumwood, Val. "Animals and Ecology: Towards a Better Integration." ANU Research Publications, 2003. www.core.ac.uk/download/pdf/156617082.pdf.

Plumwood, Val. "Integrating Ethical Frameworks for Animals, Humans, and Nature: A Critical Feminist EcoSocialist Analysis." Ethics and the Environment, 2000, pp. 285-322. JSTOR, www.jstor.org/stable/ 40338997?seq=1\#metadata_info_tab_contents. Accessed 20 Dec. 2019.

Schanck, R. L., and Charles Goodman. "Reactions to Propaganda on Both Sides of a Controversial Issue." The Public Opinion Quarterly, vol. 3, no. 1, 1939, pp. 107-112. JSTOR, www.jstor.org/stable/2744745. Accessed 16 Jan. 2020.

Shaikh, M. G., Anderson, J. M., Hall, S. K., \& Jackson, M. A. "Transient Neonatal Hypothyroidism Due to a Maternal Vegan Diet." Journal of Pediatric Endocrinology \& Metabolism, vol. 16, no.1, 2003, pp. 111-114. Retrieved from Pub Med database. http://ncbi.nlm.nih.gov/pubmed/12585349.

Sneijder, Petra, and Hedwig F.M. Te Molder. "Moral Logic and Logical Morality: Attributions of Responsibility and Blame in Online Discourse on Veganism. Discourse \& Society, vol.16,no.5,2005, pp. 675-696. JSTOR, www.jstor.org/stable/42888706.

Sturgeon, Noël. "Considering Animals: Kheel's Nature Ethics and Animal Debates in Ecofeminism." Ethics and the Environment, vol. 14, no. 2, 2009, pp. 153-162. JSTOR, www.jstor.org/stable/10.2979/ete.2009.14.2.153.

"The Product Types Ontology: Class Definition for 'Veganism."' E-Business + Web Science Research Group, www.productontology.org/doc/Veganism.

Vermillion, S. (2019, April 22). Inside Mahatma Gandhi's Search For The Perfect Diet. Retrieved from The Huffington Post website: https://www.huffpost.com/entry/mahatmagandhidiet_1_5cb6021fe4b082aab08d3954.

Vidal, David. "Propaganda in War Reporting on the U.S. War in Iraq." Stanford Edu, web.stanford.edu/class/e297a/ War\%20Reporting\%20on\%20the\%20U.S.\%20War\%20in\%20Iraq.htm. Accessed 20 Dec. 2019. 